\title{
SPATIOTEMPORAL CHANGE OF URBAN AGRICULTURE USING GOOGLE EARTH IMAGERY: A CASE OF MUNICIPALITY OF NAKHONRATCHASIMA CITY, THAILAND
}

\author{
Y.Jantakat ${ }^{1}$, P. Juntakut ${ }^{2}$, S. Plaiklang ${ }^{3}$, W. Arree ${ }^{1}$, C. Jantakat ${ }^{4}$ \\ ${ }^{1}$ Faculty of Sciences and Liberal Arts, Rajamangala University of Technology Isan; 30000 Nakhon Ratchasima, Thailand - \\ yaowaret.ja@rmuti.ac.th and (yjantakat, worapon1983)@gmail.com \\ ${ }^{2}$ Academic Division of Chulachomklao Royal Military Academy; 26001 Nakhon Nayok, Thailand - pjuntakut@crma.ac.th, \\ Juntakut37@gmail.com \\ ${ }^{3}$ Faculty of Computer Science and Information Technology, Rambhaibarni Rajabhat University, 22110 Chantaburi, Thailand - \\ sasikarn.p@rbru.ac.th \\ ${ }^{4}$ Vongchavalitkul University, 30000 Kakhon Ratchasima, Thailand - chomphak_jan@vu.ac.th
}

\section{Commission VI, WG VI/4}

KEY WORDS: Urban Agriculture, Spatiotemporal Analysis, Google Earth Imagery, Municipality of Nakhonratchasima City

\begin{abstract}
:
Presently, urban agriculture (UA) is an important part of the urban ecosystem and a key factor that can help in the urban environmental management. Therefore, this paper studies a spatial-temporal analysis of UA areas and types in Municipality of Nakhonratchasima City (MNC), Thailand. This UA types referred land use classification system of Land Development Department (LDD). Google Earth images acquired in the years of 2007, 2011, 2015 and 2018 were used to examine UA change with segmentation-based classification method in QGIS to classify Google Earth images into thematic maps. Moreover, this study showed different spatiotemporal change patterns, composition and rates in the study area and indicates the importance of analyzing UA change. Therefore, the results of this classification consisted of eleven classes - abandoned paddy field, rice paddy, abandoned field crop, mixed field crop, cassava, betel palm, mixed orchard, coconut, rose apple, truck crop, and fish farm. Truck crop had the greatest cover in study area while floricultural covered the minimal space over periods of study. The UA change analysis over time for entire study areas provides an overall picture of change trends. Furthermore, the UA change at census sector scale gives new insights on how human-induced activities (e.g., built-up areas and roads) affect UA change patterns and rates. This research indicates the necessity to implement change detection for better understanding the UA change patterns and rates.
\end{abstract}

\section{INTRODUCTION}

\subsection{Urban Agriculture}

Urban agriculture (UA) is now one important type of urban land use/cover planning or an agricultural activities in urban areas. UA provides food, economic, social and environment (Goodman and Minner, 2019; Dieleman, 2017) that types of UA includes a diversity of agriculture in both hidden and obvious patterns that is depend on that urban area's location. Meaning of UA, generally, is briefly defined as the growing of urban food areas (Weidner et al., 2019; Mackay, 2018; Pulighe and Lupia, 2016; Taylor and Lovell, 2012). On the other hand, UA plays a role of urban greenness or environment (Robineau and Dugue, 2018; Cvejic et al., 2015; Weerakoon, 2014; van Leeuwen et al., 2010). Furthermore, the present studying of UA may include peri-urban agriculture, acronym as 'UPA' that consists of growing crops, raising animals, and their associated activities either within or along the fringes of cities (de Zeeuw, van Veenhuizen, and Dubbeling 2011).

In Thailand, UA occurs a variety of types that is up to cities' policy and living. For example, Bangkok's UA is in a form of urban farming projects that support Bangkok people such as Thai city farm and veggie prince (Environnet, 2016), vertical farming concept (Kamonpatana and Anuntavoranich, 2015). For Nakhonratchsima municipality (NM)'s UA, Land development Department (LDD) from 2007 to 2015 recorded NM's UA types in from of GIS data layer that was displayed on QGIS and was found by eleven types: abandoned paddy field, rice paddy, abandoned field crop, mixed field crop, cassava, betel palm, mixed orchard, coconut, rose apple, truck crop, and fish farm. Interesting, most truck crops (higher than $70 \%$ ) covered in NM area and increased between 2007 and 2015.

\subsection{Spatiotemporal Analysis}

Spatiotemporal analysis allows spatial or time-series analyses and describes investigation (Alatorre and Begueria, 2010, monitoring (Mugiraneza et al., 2017; Haas et al., 2015), detection (Furberg and Ban, 2012) and evaluation (Haas and Ban, 2014) for the persistence of patterns over time that exists at a certain time and location. In other words, spatial and temporal studying shows the relationship between pattern and process for space and time that the used spatial and temporal data can be identified in different results (Fortin and Dale, 2005). This research reviewed spatiotemporal analysis relevant to urban agriculture areas and urban land use/land cover from various related papers such as Wellmann et al. (2018), Mugiraneza et al. (2017), Wilken et al. (2017), etc.

\subsection{Google Earth Images}

Google earth imagery is open source and is able to utilize for urban study because of providing clear view of urban land use and land cover (Malarvizh et al., 2016) and GE is a tool that provides you with the ability to view the planet through a virtual globe, and tunnel down to examine more detailed information (Harrington and Cross, 2014). Moreover, the pros of satellite images on Google earth (GE) is used for analyzing spatial data because they give the latest satellite 
imagery having spatial resolution less than $1 \mathrm{~m}$ (Malarvizh et al., 2016; Potere, D. 2008). Therefore, this study required using GE images for detecting UA. For example of using GE images related application of urban land use and UA areas included urban land use change detection (Liu et al., 2018; Malarvizhi et al., 2016); mapping UA (Pulighe and Lupia, 2016; Ringenbach et al., 2013; Taylor and Lovell, 2012).

\subsection{Concepts of Segmentation Algorithms}

Segmentation produces homogenous clusters or objects each of which is associated with additional attributes such as mean, variance, shape index, textural measures, etc. depending on the segmentation methods (Zou and Lin, 2013) and is the process of completely partitioning a scene (e.g., a remote sensing image) into non-overlapping regions (segments) in scene space (e.g., image space) (Schiewe, 2002). Image segmentation is a key component to object-based classification (Clark Labs, 2018; Humboldt State University, 2015) and still is considered to be a very crucial prerequisite, because its quality largely affects the final performance of geoobjects recognition ( $\mathrm{Su}$ and Zhang, 2017). Therefore, Principle of segmentation algorithms defines categorization of image elements based on homogeneity or heterogeneity. Therefore, segmentation methods are designed for partitioning a scene into regions are distinguished as: point-based, edge-based, region-based, and combined approaches (Mohan and Leela, 2013; Schiewe, 2002). This study used Orfeo ToolBox (OTB) in QGIS. Orfeo ToolBox (OTB), is an open-source project for remote sensing which can be integrated in QGIS, is toolbox of segmentation algorithms including watershed, mean shift, k-means etc. (Baisantry wt al., 2017). In OTB, we selected mean-shift filtering for image segmentation on GE imagery. Finally, evaluation of segmentation result consists of two types that are qualitative (not need ground truth) and quantitative (need ground truth) approaches (Su and Zhang, 2017).

\subsection{Objectives and Scope of Study}

1.5.1 Objectives: The objectives were a spatial-temporal analysis of urban agriculture (UA) areas and types in Municipality of Nakhonratchasima City (MNC), Thailand.

\subsubsection{Scope of study:}

(1) Study area was MNC, Thailand.

(2) UA types referred land use classification system of Land Development Department (LDD).

(3) Satellite images and software consisted of google earth (GE) imagery in year 2007, 2011, 2015 and 2018 and Orfeo Toolbox (OTB) in QGIS were used for analysing image segmentation.

(4) Evaluation of segmentation results used such above two-combined approach because the past GE images (e.g., year 2007-2015) cannot check in the present ground so we have to investigate with reliable source such as Land Development Department (LDD).

\section{STUDY AREA AND DATA DESCRIPTION}

\subsection{Study Area}

Municipality of Nakhonratchasima City (MNC) is located in Nakhon Ratchasima province in the North-East of Thailand region. Geographically, it is located in Southeast Asia of Equator from $14^{\circ} 56^{\prime}-15^{\circ} 00^{\prime} \mathrm{N}$ to $102^{\circ} 01^{\prime}-102^{\circ} 08^{\prime} \mathrm{E}$.

Figure 1 illustrates the location of MNC within Nakhon Ratchasima province in the North-East of Thailand region.
Land uselland cover in the study area appeared forest, agriculture, urban and built-up, abandon and water bodies. Especially, MNC's urban agriculture based land use classification system of Land Development Department (LDD) consisted of eleven types from 2007 to 2018 as follows: abandoned paddy field, rice paddy, abandoned field crop, mixed field crop, cassava, betel palm, mixed orchard, coconut, rose apple, truck crop, fish farm.

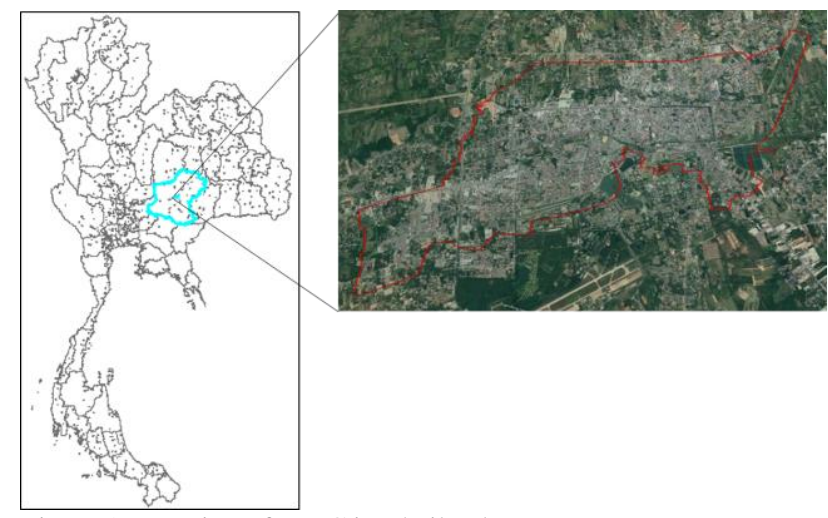

Figure 1. Location of MNC in Thailand.

\subsection{Data Description}

This study used GE imagery for detecting UA-spatiotemporal analysis in year 2007, 2011, 2015 and 2018. Satellite images were saved from Google earth program. The GE images with almost same anniversary dates were selected. The first GE images was acquired on January 11, 2007, the second GE images was acquired on December 22, 2011, the third GE images was acquired on January 16, 2015, and the fourth GE images was acquired on January 4, 2018. All acquired data were projected in Universal Transverse Mercator (UTM) with the WGS-84 datum. For image segmentation, this study used Orfeo Toolbox (OTB) in QGIS for object-based image analysis. QGIS is open source software and now is mostly implemented in remote sensing researches.

\section{METHODOLOGY}

This study showed procedure in Figure 2.

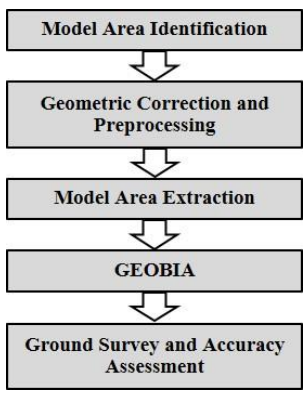

Figure 2. Procedure for this study

\subsection{Model Area Identification}

The UA-prototype areas in MNC between 2007 and 2018 consisted of eleven types such as abandoned paddy field, rice paddy, abandoned field crop, mixed field crop, cassava, betel palm, mixed orchard, coconut, rose apple, truck crop, fish farm. These were used for GEOBIA that considered UA ratio from LDD in year 2015. According to the conditions specified in the initial agreement, prototype area should have at least 100 sq.km. 


\subsection{Image Pre-Processing}

3.2.1 Geometric correction: Geometric correction used ground control point (GCP) from GE program with image to image registration - translation and rotation alignment process.

\subsection{Model Area Extraction}

GE images based multispectral data includes three bands that was done by geometric correction. It was extracted by covering the prototype areas of eleven-UA types as mentioned above and shown as Table 1.

3.2.2 Filtering techniques: Spatial filter was used for enhancement or highlight the spatial characteristics of an image dataset.

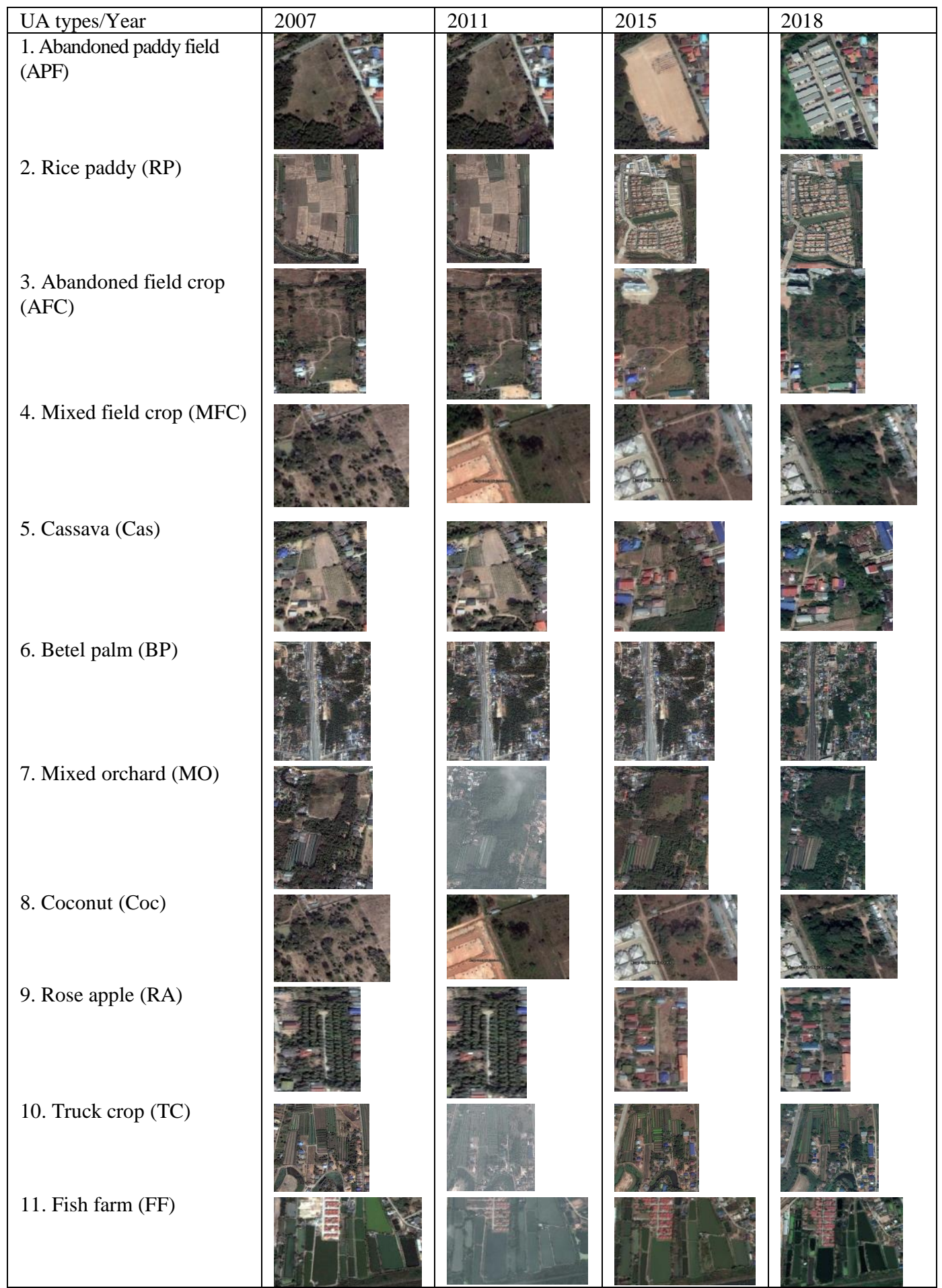

Table 1. Screenshots example of spatiotemporal analysis based UA types in same areas in year 2007, 2011, 2015 and 2018 detected by using GE image. 


\subsection{Image Segmentation}

This study used mean-shift filtering algorithm (multi-threaded) for GE image segmentation that was processed by Orfeo ToolBox (OTB) (download at https://www.orfeo-toolbox.org/) for integrating in QGIS, there are steps (OTB-Team, 2019) as follows:

3.4.1 Spatial radius (filter.meanshift.spatialr): Spatial radius of the neighborhood.

3.4.2 Range radius (filter.meanshift.ranger): Range radius defining the radius (expressed in radiometry unit) in the multispectral space.

3.4.3 Mode convergence threshold (filter.meanshift.thres): Algorithm iterative scheme will stop if mean-shift vector is below this threshold or if iteration number reached maximum number of iterations.

3.4.4 Maximum number of iterations (filter.meanshift.maxiter): Algorithm iterative scheme will stop if convergence hasn't been reached after the maximum number of iterations.

3.4.5 Minimum region size (filter.meanshift.minsize): Minimum size of a region (in pixel unit) in segmentation. Smaller clusters will be merged to the neighboring cluster with the closest radiometry. If set to 0 no pruning is done. Then it shifts the center of window to the mean

After image segmentation was done, then we classified segment.

\subsection{Ground Survey and Accuracy Assessment}

Accuracy assessment of image segmentation results included ground survey (for GE images in year 2018) and non-ground survey (for GE images in year 2007, 2011 and 2015) - was checked to LDD land use dataset. Then, these results were calculate by overall accuracy.

\section{RESULTS AND DISCUSSION}

\subsection{Results of mean shift segmentation based GE images}

\subsubsection{Results of mean shift segmentation based GE images} in eleven-UA types: The mean shift algorithm provides an efficient way to simplify (Zou and Lin, 2013) and also helps to open the original image into a multi-scale space to allow the incorporation of scale into classification $(\mathrm{Vu}, 2012)$.

In our study, Monteverdi (GUI version OTB) is employed for mean shift segmentation. A demonstration example of OTB mean-shift segmentation is shown as Table 2 (with parameters setting: spatial radius is 30 , spectral value is 45.5 , and minimum region size is 100 ).

Results of OTB mean-shift segmentation reflects that UA type of TC and FF in MNC are clearly segmented and related to true ground higher than other US types.

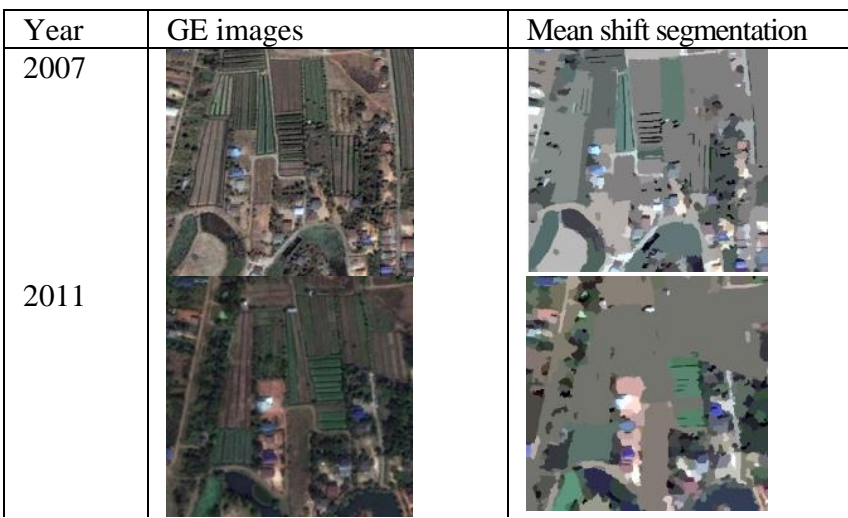

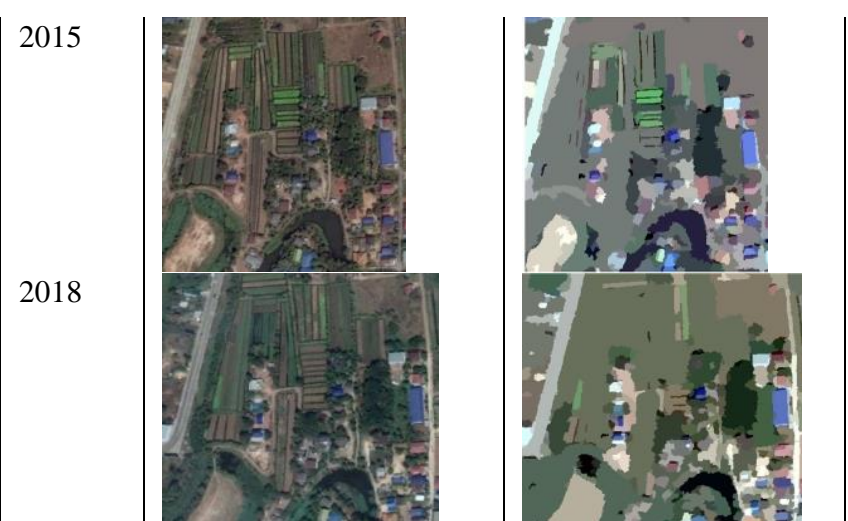

Table 2. Screenshots example of TCs for spatiotemporal analysis with mean shift segmentation in QGIS between 2007 and 2018 detected by using GE image.

4.1.2 Accuracy assessment: Accuracy assessment of overall of MNC land use about $85.56 \%$. Accuracy assessment of overall -UA types in MNC based on analysis of GE image segmentation about $82.35 \%$. For evaluation of each UA type included APF 85.51\%, RiceP 91.29\%, AFC 77.23\%, MFC $75.67 \%$, Cas $77.80 \%$, BP 76.45\%, MO 75.56\%, Coc 73.90, RA $77.67 \%$, TC $95.88 \%$, FF $98.90 \%$, respectively.

\subsection{Summary statistics and spatiotemporal characteristics of UA in MNC}

Table 3 shows overall of MNC land use from 2007 to 2018, it explored five main land use types that includes forest land (FL) (0.06 sq.km. or $0.16 \%)$, agricultural land (AL or UA) (3.24 sq.km. or $8.58 \%$ ), urban and built-up land (UBL) (32.24 sq.km. or $85.34 \%$ ), water bodies (WB) (1.04 sq.km. or $2.75 \%$, and miscellaneous land (ML) (1.20 sq.km. or 3.18\%). These information showed that the highest area was UB and the second-highest was AL.

\begin{tabular}{|c|c|c|c|c|}
\hline \multirow[t]{2}{*}{ LU types/Year } & \multicolumn{4}{|c|}{ LU Areas, sq.km (\%) } \\
\hline & 2007 & 2011 & 2015 & 2018 \\
\hline Forest land (FL) & $\begin{array}{l}0.06 \\
(0.16 \%)\end{array}$ & $\begin{array}{l}0.06 \\
(0.16 \%)\end{array}$ & $\begin{array}{l}0.06 \\
(0.16 \%)\end{array}$ & $\begin{array}{l}0.06 \\
(0.16 \%)\end{array}$ \\
\hline $\begin{array}{l}\text { Agricultural } \\
\text { land (AL or }\end{array}$ & $\begin{array}{l}3.70 \\
(9.79 \%)\end{array}$ & $\begin{array}{l}3.24 \\
(8.58 \%)\end{array}$ & $\begin{array}{l}3.24 \\
(8.58 \%)\end{array}$ & $\begin{array}{l}2.16 \\
(5.72 \%)\end{array}$ \\
\hline $\begin{array}{l}\text { Urban and } \\
\text { built-up land } \\
\text { (UBL) }\end{array}$ & $\begin{array}{l}31.60 \\
(83.64 \%)\end{array}$ & $\begin{array}{l}32.06 \\
(84.86 \%)\end{array}$ & $\begin{array}{l}32.24 \\
(85.34 \%)\end{array}$ & $\begin{array}{l}34.06 \\
(90.15 \%)\end{array}$ \\
\hline $\begin{array}{l}\text { Water bodies } \\
\text { (WB) }\end{array}$ & $\begin{array}{l}1.04 \\
(2.75 \%)\end{array}$ & $\begin{array}{l}1.04 \\
(2.75 \%)\end{array}$ & $\begin{array}{l}2.75 \\
(1.04 \%)\end{array}$ & $\begin{array}{l}1.04 \\
(2.75 \%)\end{array}$ \\
\hline $\begin{array}{l}\text { Miscellaneous } \\
\text { land (ML) }\end{array}$ & $\begin{array}{l}1.38 \\
(3.65 \%)\end{array}$ & $\begin{array}{l}1.38 \\
3.65 \%)\end{array}$ & $\begin{array}{l}3.18 \\
(0.46 \%)\end{array}$ & $\begin{array}{l}0.46 \\
(1.22 \%)\end{array}$ \\
\hline Total & & 37.7 & $100 \%)$ & \\
\hline
\end{tabular}

Table 3. Summary statistics of MNC land use of Thailand classified into the five types.

Table 4 show the analysis of the size area range of the UA (or agricultural land, AL) in MNC reveals a spatial relationship with UA types and agricultural land use. The following size ranges of areas' size were analysed by from 2007 - 2018: APFs (0.229-0.212 sq.km.), RPs (0.014-0.027 sq.km.), AFCs (00.011 sq.km.), MFCs (0-0.116 sq.km), Cas (0.105-0.178 sq.km), BP (0.076-0.77 sq.km.), MO (0.030-0.039 sq.km.), Coc (0.089-0.090 sq.km.), RA (0-0.008 sq.km.), TC (1.305-2.687 sq.km.), and FF (0.309-0.325 sq.km.). The highest area range is TC while the lowest area range is RA. Most UA spatial and temporal distribution from 2007 to 2018 were scattered in 
surrounding the north-western and south-western edge of study area in except TCs were seen nearly Takhong Kao river. Interesting, TCs were mostly provided and occupied in MNC area because urban people required them. Most TCs' species were occurred as an eligible vegetation and green health such as morning glory, aubergine, cowpea, cabbage, lettuce, etc.

\begin{tabular}{|l|l|l|l|l|}
\hline \multirow{2}{*}{$\begin{array}{l}\text { UA } \\
\text { types/Year }\end{array}$} & \multicolumn{4}{|c|}{ UA Areas, sq.km (\%) } \\
\cline { 2 - 5 } APF & 2007 & 2011 & 2015 & 2018 \\
& 0.229 & 0.229 & 0.229 & 0.212 \\
RP & $(6.20 \%)$ & $(7.07 \%)$ & $(7.21 \%)$ & $(9.80 \%)$ \\
& 0.027 & 0.014 & 0.014 & 0.014 \\
AFC & $(0.73 \%)$ & $(0.44 \%)$ & $(0.45 \%)$ & $(0.65 \%)$ \\
& 0 & 0.011 & 0 & 0 \\
MFC & 0.116 & $(0.34 \%)$ & & \\
& $(3.14 \%)$ & & 0 & 0 \\
Cas & 0.105 & 0.178 & 0.128 & 0.126 \\
& $(2.83 \%)$ & $(5.50 \%)$ & $(4.03 \%)$ & $(5.85 \%)$ \\
BP & 0.077 & 0.076 & 0.076 & 0.076 \\
& $(2.07 \%)$ & $(2.34 \%)$ & $(2.38 \%)$ & $(3.50 \%)$ \\
MO & 0.039 & 0.030 & 0.030 & 0.030 \\
& $(1.04 \%)$ & $(0.92 \%)$ & $(0.94 \%)$ & $(1.39 \%)$ \\
Coc & 0.090 & 0.090 & 0.089 & 0.089 \\
& $(2.42 \%)$ & $(2.77 \%)$ & $(2.81 \%)$ & $(4.13 \%)$ \\
RA & 0.008 & 0 & 0 & 0 \\
& $(0.23 \%)$ & & & \\
TC & 2.687 & 2.305 & 2.306 & 1.305 \\
& $(72.57 \%)$ & $(71.06 \%)$ & $(72.44 \%)$ & $(60.38 \%)$ \\
FF & 0.325 & 0.310 & 0.310 & 0.309 \\
& $(8.77 \%)$ & $(9.57 \%)$ & $(9.75 \%)$ & $(14.31 \%)$ \\
Total & 3.702 & 3.244 & 3.183 & 2.161 \\
& $(100 \%)$ & $(100 \%)$ & $(100 \%)$ & $(100 \%)$ \\
\hline
\end{tabular}

Table 4. Summary statistics of UA sites identified in MNC of Thailand classified into the eleven types.

\subsection{UA data and potentials in MNC planning}

In our study, spatio-temporal transitions reveal interesting findings regarding TC areas - a continuous growing TC movement and expansion from 2007 -2018 of cultivated areas on vacant lots where private areas are. Therefore, potential implications for MNC planning and management should find the suitable and potential areas of TC for MNC planning and management especially food supply and urban green spaces.

\section{CONCLUSION AND FUTURE RESEARCH}

\subsection{Conclusion}

As row material to produce geo-data, timely high resolution satellite images can be acquired from Google Earth by several approaches. In this study, an Internet browser based acquisition method is introduced. Orfeo Toolbox as a free and open-source library for remote sensing task is hardy and helpful for satellite imagery analysis and feature extraction. Results of OTB meanshift segmentation reflects that UA type of TC and FF in MNC are clearly segmented and related to true ground higher than other US types.

The analysis of the size area range of the UA (or agricultural land, $\mathrm{AL}$ ) in MNC reveals a spatial relationship with UA types and agricultural land use. Most UA spatial and temporal distribution from 2007 to 2018 were scattered in surrounding the north-western and south-western edge of study area in except TCs were seen nearly Takhong Kao river. Interestingly, TCs were mostly provided and occupied in MNC area because urban people required them. Most TCs' species were occurred as an eligible vegetation and green health such as morning glory, aubergine, cowpea, cabbage, lettuce, etc.

Therefore, potential implications for MNC planning and management should find the suitable and potential areas of TC for MNC planning and management especially food supply and urban green spaces.

\subsection{Future Research}

The future work will be suggested as follows: (1) other advanced statistics (e.g. deep learning, $\mathrm{R}$ analysis) should be combined in image segmentation, (2) Finding the suitable and potential of TC areas should be suggested for MNC and concerned officials in planning and management of MNC area, and (3) TC species should be studied.

\section{ACKNOWLEDGEMENTS}

The research of Spatiotemporal Change of Urban Agriculture using Google Earth Imagery: A Case of Municipality of Nakhonratchasima City, Thailand is continued from the research of Applied Geo-Informatics Technology to Urban Green Space Management on Role of Stormwater Runoff Reducing and Increasing of Subsurface Water in Nakhonratchasima City Municipality was supported by National Research Council Thailand (NRCT) scholarship in year 2017. The authors thank to Faculty of Sciences and Liberal Arts of Rajamangala University of Technology Isan to support fund for presenting this paper.

\section{REFERENCES}

Alatorre, L.C. and Begueria, S., 2010. Analysis of Spatial and Temporal Evolution of the NDVI on Vegetated and Degraded Areas in The Central Spanish Pyrenees. Int. Arch. Photogramm. Remote Sens. Spatial Inf. Sci., XXXVIII-Part7A, 7-12.

Baisantry, M., Shukla, D. P., Bansal, G. 2017. Evaluation of Object-based Image Analysis Software for segmentation in Remote Sensing Applications. Int. Arch. Photogramm. Remote Sens. Spatial Inf. Sci., AGILE - Wageningen.

Clark Labs, 2018. Segmentation and Segment-based Classification. From https://clarklabs.org/segmentation-andsegment-based-classification/

Cvejic, R., Zeleznikar, S., Nastram, M., Rehberger, V. and Pintar, M. 2015. Urban Agriculture as a Tool for Facilitated Urban Greening of Sites in Transition: A Case Study. Urbanistični inštitut Republike Slovenije, Vol 26, S84-S97.

de Zeeuw, H., R. van Veenhuizen, and M. Dubbeling. 2011. "The Role of Urban Agriculture in Building Resilient Cities in Developing Countries.” Journal of Agricultural Science 149 (S1):153 - 163 .

Dieleman, H. 2017. Urban agriculture in Mexico City; balancing between ecological, economic, social and symbolic value. Journal of Cleaner Production, 163, S156-S163.

Environnet, 2016. Urban Farming. http://www.environnet.in.th/en

Fortin, M.-J. and Dale, M. 2005. Spatial Analysis: A Guide for Ecologist. Cambridge University Press. 
Furberg, D, \& Ban, Y. 2012. Satellite monitoring of urban sprawl and assessment of its potential environmental impact in the Greater Toronto Area between 1985 and 2005. Environmental management, 50(6), 1068-1088.

Goodman, W. and Minner, J. 2019. Will the urban agricultural revolution be vertical and soilless? A case study of controlled environment agriculture in New York City. Land Use Policy, $83,160-173$.

Haas, J, \& Ban, Y. 201). Urban growth and environmental impacts in Jing-Jin-Ji, the Yangtze, River Delta and the Pearl River Delta. International Journal of Applied Earth Observation and Geoinformation, 30, 42-55.

Haas, J, \& Ban, Y. (2015). Synergy of Sentenel-1A SAR and Sentenel-2A MSI data for urban ecosystem service mapping. Paper presented at the 35th EARSeL Symposium - European Remote Sensing: Progress, Challenges and Opportunities, Stockholm, Sweden, June 15-18 2015.

Harrington, M. and Cross, M. 2014. Google Earth Forensics: Using Google Earth Geo-Location in Digital Forensic Investigations. From https://www.sciencedirect.com/book/9780128002162/google-earthforensics\#book-description

Humboldt State University, 2015. Object-based Classification. From http://gsp.humboldt.edu/olm_2015/Courses/GSP_216_Online/lesson6 $-1 /$ object.html

Kamonpatana, K. and Anuntavoranich, P. 2013. Vertical Farming Concept in Thailand: Important Decision Variables. International Journal of Innovative Research in Science, Engineering and Technology, ISSN online (2319-8753), 23476710 .

Land development Department (LDD). 2007. Land Use Map for Nakhon Ratchasima Province [CD-ROM]. Bangkok, Thailand.

Land development Department (LDD). 2011. Land Use Map for Nakhon Ratchasima Province [CD-ROM]. Bangkok, Thailand.

Land development Department (LDD). 2015. Land Use Map for Nakhon Ratchasima Province [CD-ROM]. Bangkok, Thailand.

Liu, X., Hu G., Chen, Y. Li, X. Xu, X. Li, S. Pei, F., Wang, S. 2018. High-resolution multi-temporal mapping of global urban land using Landsat images based on the Google Earth Engine Platform. Remote Sensing of Environment 209 (1), 227-239.

Mackay, H. 2018. Mapping and characterizing the urban agricultural landscape of two intermediate-sized Ghanaian cities. Land Use Policy, 70, 182-197.

Malarvizhi, K., Vasantha Kumar, S. Porchelvan, P. 2016. Use of High Resolution Google Earth Satellite Imagery in Landuse Map Prepration for Urban Related Applications. Procedia Technology, 24(1), 1835-1842.

Mohan, S. S. and Leela, S. 2013. Importance of Mean Shift in Remote Sensing Segmentation. IOSR Journal of Computer Engineering, 14 (6), 80-83.

Mugiraneza, T., Haas, J. and Ban, Y., 2017. Spatiotemporal Analysis of Urban Land Cover Changes in Kigali, Rwanda using Multitemporal Landsat Data and Landscape Metrics. Int.
Arch. Photogramm. Remote Sens. Spatial Inf. Sci., XLII-3/W2, 137-144.

OTB-Team. 2019. Segmentation. From https://www.orfeotoolbox.org/Applications/Segmentation.html

Robineau, O. and Dugue, P. 2018. A socio-geographical approach to the diversity of urban agriculture in a West African city. Landscape and Urban Planning, 170, 48-58.

Potere, D. 2008. Horizontal Positional Accuracy of Googlr Earth's High Resolution Imagery Archive. Sensors 8(1), 79737981, DOI 10.3390/88127973

Pulighe, G. and Lupia, F. 2016. Mapping spatial patterns of urban agriculture in Rome (Italy) using Google Earth and webmapping services. Land Use Policy, 59, 49-58.

Ringenbach, J., Valcourt, m. and Wang, W. 2013. Mapping the Potential for Urban Agriculture in Worceseter: A Land Inventory Assessment. Worcester Polytechnic Institute, 133 p.

Su, T. and Zhang, S. 2017. Local and global evaluation for remote sensing image segmentation. ISPRS Journal of Photogrammetry and Remote Sensing, 130 (1), 256-276.

Schiewe, J., 2002. Segmentation of High-Resolution Remotely Sensed Data - Concepts, Applications and Problems. Int. Arch. Photogramm. Remote Sens. Spatial Inf. Sci., XXXIV Part4

Taylor, J. R. and Lovell, S. T., 2012. Mapping public and private spaces of urban agriculture in Chicago through the analysis of high-resolution aerial images in Google Earth. Landscape and Urban Planning, 108 (1), 57-70.

van Leeuwen, E., Nijkamp, P., and de Noronha Vaz, T. 2010. The multifunctional use of urban

greenspace. International Journal of Agricultural Sustainability, 8, 20-25.

Vu, T.T. 2012. Object-Based Remote Sensing Image Analysis with OSGeo Tools. In AGSE 2012 FOSS4G-SEA, p. 79.

Weerakoon, K. 2014. Suitability Analysis for Urban Agriculture Using GIS and Multi-Criteria Evaluation. International Journal of Agricultural Science and Technology (IJAST), Vol 2, Issue 2, 10.14355/ijast.2014.0302.03

Weidner, T., Yang, A. and Hamm, M. W. 2019. Consolidating the current knowledge on urban agriculture in productive urban food systems: Learnings, gaps and outlook. Journal of Cleaner Production, 209, 1637-1655.

Wellmnn, T., Haase, D., Knapp, S., Salbach, C., Selsam, P., Lausch, A. 2018. Urban land use intensity assessment: The potential of spatio-temporal spectral traits with remote sensing. Ecological Indicators, (85 (1), 190-203.

Wilken, F., Wagner, P. D., Narasimhan, B. and Fiener, P. 2017. Spatio-temporal patterns of land use and cropping frequency in a tropical catchment of South India. Applied Geography, 89 (1), 124-132.

Zou, Z. and Lin, X. 2013. Geoinformatics Production for Urban Disasters Risk Reduction: A Zero Cost Solution. F. Bian et al. (Eds.): GRMSE, Part I, CCIS 398 pp., 313-324, SpringerVerlag Berlin Heidelberg. 